

\section{The Model for Sustainable Mental Health: Future Directions for Integrating Positive Psychology Into Mental Health Care}

\author{
Ernst Bohlmeijer ${ }^{1,2 *}$ and Gerben Westerhof ${ }^{1,2}$ \\ ${ }^{1}$ University of Twente, Enschede, Netherlands, ${ }^{2}$ Center for eHealth and well-being, Enschede, Netherlands
}

\section{OPEN ACCESS}

Edited by:

Llewellyn Ellardus Van Zyl, Optentia, North West University,

South Africa

Reviewed by:

Sebastiaan Rothmann, North-West University, South Africa

Leoni Van Der Vaart, North-West University, South Africa

*Correspondence: Ernst Bohlmeijer e.t.bohlmeijer@utwente.nl

Specialty section: This article was submitted to

Positive Psychology, a section of the journal Frontiers in Psychology

Received: 27 July 2021 Accepted: 13 September 2021 Published: 21 October 2021

Citation:

Bohlmeijer E and Westerhof G (2021)

The Model for Sustainable Mental

Health: Future Directions for

Integrating Positive Psychology Into

Mental Health Care.

Front. Psychol. 12:747999.

doi: 10.3389/fpsyg.2021.747999
This position paper proposes a model for systematic integration of positive psychology interventions (PPIs) in mental healthcare. On the one hand, PPIs can contribute to the decrease of dysfunctional processes underlying mental illness. This evidence is at the core of the new domains of positive clinical psychology and positive psychiatry. On the other hand, a growing number of studies demonstrate that mental health is not merely the absence of mental illness. Mental wellbeing represents a related but separate dimension of mental health. Mental wellbeing reduces the risk of future incidence of mental illness and is highly valued by people receiving psychological treatment as an important aspect of personal and complete recovery and personal growth. This makes mental wellbeing a vital outcome of mental healthcare. PPIs can directly increase mental wellbeing. The model of sustainable mental health is presented integrating the science of positive psychology and mental wellbeing into mental healthcare. This heuristic model can guide both practitioners and researchers in developing, implementing, and evaluating a more balanced, both complaint- and strength-oriented, treatment approach. The role of gratitude interventions is discussed as an example of applying the model. Also, three potential modalities for implementing PPIs as positive psychotherapy in treatment are as: positive psychotherapy as primary treatment, as combinatorial treatment, and as intervention for personal recovery of people with severe or persistent mental disorder. Finally, we argue that longitudinal studies are needed to substantiate the model and the processes involved.

Keywords: positive psychology, mental health care, intervention, implementation model, integration

\section{INTRODUCTION}

Positive psychological interventions (PPIs) aim to enhance resources that enable people to be resilient and flourish. Some examples of evidence-based PPIs are: savoring, gratitude, kindness, optimism, promoting positive relationships, and pursuing meaning (Schueller and Parks, 2014). Though PPIs have been developed to promote happiness and optimal functioning in diverse groups like people who would like to grow and develop, children at school, workers in business (Seligman and Csikszentmihalyi, 2000; Linley et al., 2006), from the beginnings of positive psychology as a scientific domain, PPIs have been studied in clinical populations as well 
(Seligman et al., 2006). PPIs, aiming to promote positive affect, engagement, and social relationships, may improve response of psychological and psychiatric treatments of mental disorders which have led to initiatives to integrate positive psychology in clinical psychology (Wood and Tarrier, 2010; Wood and Johnston, 2016) and in psychiatry (Jeste and Palmer, 2015; Fava and Guidi, 2020).

In the past years, a rapidly growing number of studies have evaluated the effects of PPIs on mental health in clinical populations. Chakhssi et al. (2018) indeed found small to moderate effect sizes of PPIs on wellbeing, depression, and anxiety in clinical populations across 30 studies. In a recent comprehensive metaanalysis on the impact of PPIs, an average moderate effect on mental wellbeing was found, based on 60 studies in clinical populations (Carr et al., 2020). On the other hand, another recent meta-analysis has shown that a broad range of psychological interventions can contribute to the promotion of wellbeing in both clinical and non-clinical populations (van Agteren et al., 2021). In persons with mental illness, cognitive (behavioral) therapy had similar small to moderate effects on wellbeing as singular and multi-component PPIs.

Hence, an important question is how we can better understand the mutual effects of PPIs and more traditional psychological interventions on both mental wellbeing and mental illness. In this position paper, we present a heuristic model of sustainable mental health, systematically integrating PPIs in mental healthcare. We will first describe the model that is informed by empirical research but is mainly a theoretical proposition. Next, we use gratitude as an example of how it can be applied. We present three potential modalities for implementing PPIs as positive psychotherapy in treatment and close with directions for further research.

\section{MENTAL WELLBEING AS A VITAL OUTCOME OF MENTAL HEALTHCARE}

The first step in developing the sustainable mental health model relates to the recognition that mental wellbeing is an important outcome in mental healthcare, besides mental illness. "Mental health is simply too important to be ignored" wrote eminent scholar George Vaillant (2003). The dominant focus in psychological treatment has long been on mental disorders and symptoms of psychopathology. Mental health, however, is more than the absence of mental illness. The World Health Organization accentuates the positive dimension of mental health defining it as "a state of well-being in which the individual realizes his or her own abilities, can cope with the normal stresses of life, can work productively and fruitfully, and is able to make a contribution to his or her community" (World Health Organization, 2005, p.2). The three core components of this definition are (1) feeling well, (2) effective functioning of an individual, and (3) effective functioning for a community.

In this definition, one can also recognize two traditions of wellbeing: one focusing on hedonic wellbeing and the other on eudaimonic wellbeing (Waterman, 1993; Ryan and Deci, 2001).
There is widespread consensus that hedonic wellbeing is a multidimensional concept, including evaluations of life in emotional terms (i.e., life-satisfaction) as well as the presence of positive and absence of negative affect (Diener, 1984; Diener et al., 1999). The concept of eudaimonia dates back to Aristotle, for whom not subjective happiness, but the realization of one's own potential in a societal context was the essential element of a good life (Waterman, 1993). Several models have been put forward for eudaimonic wellbeing, such as psychological wellbeing (Ryff, 2014) and self-determination theory (Ryan and Deci, 2017). Keyes (2005) developed a model of mental health in which emotional, psychological, and social wellbeing are all important indicators of a flourishing life.

Three key findings have emerged from studies on the relation between mental wellbeing and mental illness in the past decades. First, there is substantial evidence for the so-called two-continua model. This model holds that mental wellbeing and mental illness are related, yet discernible phenomena: One continuum represents the presence or absence of mental wellbeing and the other the presence or absence of mental illness. Superiority of a two-related factors model has been demonstrated in large representative surveys (Keyes, 2005; Westerhof and Keyes, 2010; Lamers et al., 2011; Weich et al., 2011; Schotanus-Dijkstra et al., 2017) as well as in clinical samples (Trompetter et al., 2017; De Vos et al., 2018; Franken et al., 2018). Evidence for mental wellbeing and mental illness as distinct dimensions also comes from, for example, health and life-style surveys (Huppert and Whittington, 2003) and life span studies (Westerhof and Keyes, 2010; Lamers et al., 2012).

Secondly, longitudinal evidence indicates that higher levels of mental wellbeing reduce the risk of incident mental health issues and mental disorders (e.g., Keyes et al., 2010; Wood and Joseph, 2010; Grant et al., 2013; Lamers et al., 2015; Schotanus-Dijkstra et al., 2017).

Thirdly, whereas the two-continua model has been developed from studies in the general population, studies on perspectives of mental healthcare users have made a difference between clinical and personal recovery (Slade, 2010). Based on a systematic review and narrative synthesis of qualitative studies on personal recovery, Leamy et al. (2011) developed the so-called CHIME model to describe five personal recovery processes: Connectedness, Hope and optimism, Identity, Meaning in life, and Empowerment. Although this model uses different terminology, there is a clear overlap with approaches to eudaimonic aspects of wellbeing. A systematic review and qualitative meta-analysis synthesized findings of qualitative studies on perspectives of persons who recovered from eating disorders in line with the two-continua model (de Vos et al., 2017). Besides a decrease in eating disorders-related behaviors and cognitions, they described improvements in self-acceptance, positive relationships, personal growth, self-adaptability/resilience, and autonomy as most fundamental criteria in their recovery process. Besides a reduction in complaints, these findings show that psychological wellbeing plays an important role in the recovery process for these persons. Hence, it can be concluded that the patient perspective also considers wellbeing an essential part of recovery processes. 
Over the past years, many instruments have been developed to measure different aspects of mental wellbeing. An overview with as many as 99 instruments to measure mental wellbeing is available (Linton et al., 2010). Among the most often used are the Positive and Negative Affect Schedule, the Satisfaction with Life Scale, Ryff's Scales of Psychological Well-being, the Warwick-Edinburg Mental Well-Being Scale, the Flourishing scale, and the Mental Health Continuum Short Form. A number of measures have also been developed for personal recovery (Van Weeghel et al., 2019), such as the Recovery Assessment Scale, the Stages of Recovery Instrument, and the Questionnaire on Personal Recovery. There is nowadays good evidence that people can provide valid and reliable self-reports of wellbeing (Diener et al., 2018).

In studies on the two-continua model, the Mental Health Continuum Short Form (Keyes et al., 2008) has become the most often used instrument. The instrument is solidly grounded in theoretical syntheses on subjective wellbeing and optimal psychological and social functioning with each item measuring a separate aspect of wellbeing. A recent meta-analytic structural equation model across 26 studies provided strong evidence of a general factor of mental wellbeing as well as three separate dimensions of emotional, psychological, and social wellbeing in both clinical and non-clinical samples (Iasiello et al., in press).

To summarize, growing evidence suggests that mental wellbeing is a vital outcome in mental healthcare that can be measured with reliable and valid instruments. Integrating PPIs in mental healthcare might contribute to a stronger focus on mental wellbeing in mental healthcare practice. However, PPIs are not meant to replace or compete with other wellestablished psychological treatments in mental healthcare but to complement them. But this raises the question how to optimally integrate PPIs in mental healthcare? To this end, we developed the model of sustainable mental health.

\section{THE MODEL FOR SUSTAINABLE MENTAL HEALTH}

Figure 1 presents a model aiming to integrate dysfunctional and functional perspectives on mental health and psychological treatment. It is meant as a heuristic model guiding researchers and practitioners to develop, implement, and evaluate a more balanced, both complaints- and wellbeing-oriented, treatment approach. It is beyond the scope of this paper to discuss all components of the model in detail, but we give a brief overview of outcomes, adaptation, context, underlying processes, and interventions as main components of the model (Bohlmeijer and Westerhof, 2021).

A first component in this model is that sustainable mental health incorporates mental wellbeing as an essential mental health outcome besides mental illness as discussed in the previous section.

The second component refers to adaptation processes as inhibiting or promoting sustainable mental health. The absence of psychological complaints and the presence of mental wellbeing can easily be taken as normative endpoints. However, life is characterized by moments of suffering as well as flourishing. As both continua of mental health will fluctuate across time in a dynamic reciprocal process, it is important to better understand how people regulate their mental health, not in the least because that may also provide possibilities for psychological interventions. We therefore added adaptation processes to the model. Psychosocial adaptation can be seen as a process by which a person interacts with the psychosocial consequences of smaller or larger challenges in life. A common view is that temporality plays an important role in adaptation (Livneh, 2001). Short-term challenges include day-to-day moments that often involve emotions, such as anger, anxiety, or depression. These short-term reactions ask for coping processes that mainly focus on the reduction of stress (Lazarus and Folkman, 1984). Intermediate challenges may be referred to as self-management, which includes dealing with symptoms of illness, communication with health professionals, or adopting life-style changes (Barlow et al., 2002; Loriq and Holman, 2003). Lastly, there are longer term challenges that ask for assimilation and accommodation of life-goals, identity, and meaning in life. These processes are related to aspects of narrative identity development in which the way people identify with and distance themselves from difficult life experiences is key in the regulation of mental health and wellbeing (Westerhof and Bohlmeijer, 2012).

Besides the temporal aspect of adaptation processes, the regulatory focus of these processes might differ. A large body of psychological literature that is of interest to chart adaptation processes has focused on how to deal with stress, symptoms, and illnesses. These processes are mainly important in regulating the illness continuum of mental health, often with a reactive focus on solving problems, restoring previous levels of functioning, or bouncing back to an earlier equilibrium. More recently, a number of processes have been put forward in positive psychology that have a stronger focus on maintaining or promoting wellbeing, like the attention for positive emotions or the use of strengths, virtues, and values (Fredrickson, 2001; Lyubomirsky et al., 2005) and psychological flexibility (Kashdan and Rottenberg, 2010). Processes involved include, for example, benefit finding (Tennen and Affleck, 2005), post-traumatic growth (Tedeschi and Calhoun, 1995), and sense of coherence (Antonovsky, 1993). These processes focus more on the maintenance and promotion of wellbeing, despite the presence of problems and stress, or even on growth in wellbeing due to problematic or stressful experiences.

Thirdly, people may experience both barriers and resources for their adaptation processes. Many theories on mental illness as well as those on mental wellbeing distinguish between both in relationship to outcomes. Examples of wellstudied barriers are information processing biases and negative biases in thinking, such as overgeneralization and magnification or minimization, dysfunctional schema and beliefs about the world and oneself, and suppression of emotions and avoidance behavior. Examples of resources are the ability to experience and amplify positive emotions, optimism, the awareness and use of strengths, values, selfaffirmations, and positive relationships. We prefer the concepts of barriers and resources over, for example, negative and 




FIGURE 1 | Model of sustainable mental health

positive. The presence of negative emotions and cognitions, for example, can be functional in adaptation processes as they direct attention to important issues in the process. Over time, however, they may become dysfunctional when emotion regulation and coping strategies are inadequate and do not result in decreases of symptoms or increases in mental wellbeing.

Fourthly, contextual factors play an important role in supporting or thwarting individual attempts to maintain and achieve sustainable mental health. Ecological systems, such as relationships, parents, organizations, and communities, may either cause or maintain dysfunctional or maladaptive cognitions or behaviors that are related to mental illnesses or distress or may enhance resources that promote adaptation and mental health (Bronfenbrenner, 1995). It is important to acknowledge that the social, historical, and cultural context play an important role in supporting or thwarting individual attempts to maintain and achieve mental health. Although in this paper, we mainly focus on individual aspects of the model, this does not mean that individuals are solely responsible for managing their mental wellbeing and illness.

The fifth component is the spectrum of psychological treatments and interventions and their focus on targeting barriers or resources for successful adaptation. We propose that psychological treatments can be ordered on a spectrum, depending on whether their primary focus is on targeting barriers or resources for successful adaptation. At one end of the spectrum is psychological treatments or interventions that primarily target barriers for successful adaptation, e.g., CBT may target dysfunctional cognitions and avoidance behavior and schema therapy will target dysfunctional schema about the world and oneself. At the other end of the spectrum is psychological treatments or interventions, such as PPIs that primarily focus on developing and using resources for adaptation.

It is important to stress that many psychological treatments will comprise interventions targeting both barriers and resources for adaptation. One example is Acceptance and Commitment Therapy (ACT). ACT is a distinctive model of behavioral and cognitive therapy with a strong focus on the context of behavior (Hayes et al., 2013). It is based on a relational frame model that links behavioral principles of psychological flexibility to both pathology and flourishing (Ciarrochi and Kashdan, 2013; Hayes et al., 2013). ACT targets both barriers, such as experiential avoidance, and resources, such as awareness of and commitment to personal values. Hence, promoting sustainable mental health is a core focus in ACT (Bohlmeijer et al., 2015; Fledderus et al., 2015; White et al., 2017).

The model of sustainable mental health makes clear that there are several pathways to the different outcomes of mental illness and mental wellbeing. For example, an intervention may lead to fewer symptoms which in turn are related to more wellbeing. Or more specifically, an intervention might focus on strengthening resources that contribute to better adaptation and thereby to both mental wellbeing and mental illness. These kinds of processes might explain why PPIs can have an effect on mental illness (Chakhssi et al., 2018) as well as why CBT can have effects on wellbeing (van Agteren et al., 2021). However, it would be important to address the different barriers and resources as well as the aspects of adaptation and mental illness and mental wellbeing that are involved. We discuss these processes in some details regarding gratitude as an example. 


\section{GRATITUDE}

In this section, we want do discuss how gratitude as an example of a PPI fits into the model. Gratitude has been defined as both a positive affect resulting from the perception of receiving a benefit from another person (McCullough et al., 2002) and a trait, which includes the ability to appreciate simple things in life, sense of abundance and experience, and express gratitude toward others (McCullough et al., 2002; Watkins et al., 2003; Wood et al., 2010). People with gratitude as a stable character strength will also more frequently experience gratefulness as a positive emotion in daily life as they tend to notice and appreciate positive events and contributions of other people more often and more intensely (McCullough et al., 2002). A growing number of longitudinal studies have demonstrated the positive relation between gratitude and mental health (Wood et al., 2010). For example, it has been found that higher levels of gratitude predict improvements in wellbeing and distress over time for various populations, such as healthy adults (Disabato et al., 2017), heart patients (Millstein et al., 2016), people with rheumatic disorders (Sirois and Wood, 2017), and war veterans (Kashdan et al., 2006).

The most frequent studied gratitude interventions are the gratitude journal and gratitude letters (Emmons, 2013). The gratitude journal intervention invites people to write every day for 10 or $15 \mathrm{~min}$ about events and experiences they are grateful for. In the gratitude letter intervention, people write a letter to person expressing their gratitude explaining how the other person has had a positive impact on one's life. People are then invited to visit the other person and read the letter out aloud. In both interventions, writing in detail about the experienced benefits is a key working mechanism of gratitude. Reviews found limited and inconclusive evidence for the efficacy of mainly brief gratitude interventions (Wood et al., 2010; Davis, 2016; Dickens, 2017). However, recent studies showed a substantial impact on mental health of gratitude interventions of longer duration (Heckendorff et al., 2019; Bohlmeijer et al., 2021).

Figure 2 shows the potential impact of gratitude interventions within the model of sustainable mental health.

First of all, gratitude interventions may build resources that promote adaptation and contribute to mental health. For example, gratitude interventions aim to enhance the daily experience of gratefulness as a positive emotion. The broaden-and-build theory (Fredrickson, 2001) demonstrates how gratitude and other positive emotions contribute to a more broadened thoughtaction repertoire. This broadened repertoire sets into motion two positive spirals. First, it will promote the likelihood of discovering meaning in upcoming events, increasing the experience of positive affect in the near future (Fredrickson and Joiner, 2002). Secondly, over time positive emotions cause a positive spiral building durable physical, cognitive, and social resources promoting the ability to adapt and mental health Thus, gratitude as a life-orientation will directly contribute to mental wellbeing by a tendency toward noticing and appreciating the positive in the world and gratitude as a positive affect will decrease distress by building mental flexibility (Wood et al., 2010). Longitudinal studies have found a relationship between gratitude and negative mental states, such as depression mediated by positive emotions (e.g., Lambert et al., 2012). Also, gratitude interventions may promote the use of adaptive coping-styles, such as positive reframing. Positive reframing is the ability to develop positive interpretations of events that are firstly experienced as negative. An example is when an adverse lifeevent is considered as an opportunity to deepen a relation or develop new skills. Several studies have found evidence for the mediational role of positive reframing in the relationship between gratitude and mental health (Lambert et al., 2009, 2012). Watkins et al. (2008) found that grateful processing was beneficial in bringing closure to negative emotional memories. Finally, there is also ample evidence demonstrating that experiencing and expressing gratefulness supports the development and maintenance of high-quality relationships (e.g., Algoe et al., 2010; Grant and Gino, 2010; Lambert and Fincham, 2011; Algoe and Zhaoyang, 2016). Experiencing gratitude draws our attention to people who, by their small or major gesture, demonstrate that they care for us and are responsive to us (Algoe et al., 2013). By expressing appreciation, we confirm emotional closeness with the other person. Receiving appreciated benefits and expressing gratitude promotes shared joy and reciprocal kindness, relationship satisfaction, and willingness to invest in the relationship, all key positive, interpersonal processes (Algoe, 2019). High-quality relationships have been found to play a vital role in mental health (e.g., Thoits, 2011).

Secondly, gratitude interventions may impact barriers for adaptation. One such barrier is repetitive negative thinking. This is considered an important transdiagnostic risk factor for psychopathology (Spinhoven et al., 2015) comprising sustained focus on and difficulty to disengage from negative content. Gratefulness promotes noticing and appreciating positive experiences and this may train people to shift their attentional focus from negative experiences to more positive ones. Several studies have found evidence for the beneficial effects of gratitude interventions on repetitive negative thinking (Heckendorf et al., 2019). However, the relation between gratitude and barriers may also work the other way around. One example is the presence of a dysfunctional attachment style. People who score high on attachment-related anxiety have difficulties in trusting that a partner will be responsive in times of need, and people with an attachment-avoidance profile are more distrustful of the goodwill of other people (Brennan et al., 1998; Mikulincer and Shaver, 2009). People with strong attachment issues will have difficulties in noticing and appreciating good intentions and deeds of other people and in expressing gratefulness. Thus, the presence of attachment issues may inform the practitioner not to indicate gratitude as an intervention.

\section{COMBINING POSITIVE PSYCHOTHERAPY WITH COMPLAINT- ORIENTED TREATMENTS}

In the last section, we discussed gratitude as an example of one positive psychology intervention. In the context of 


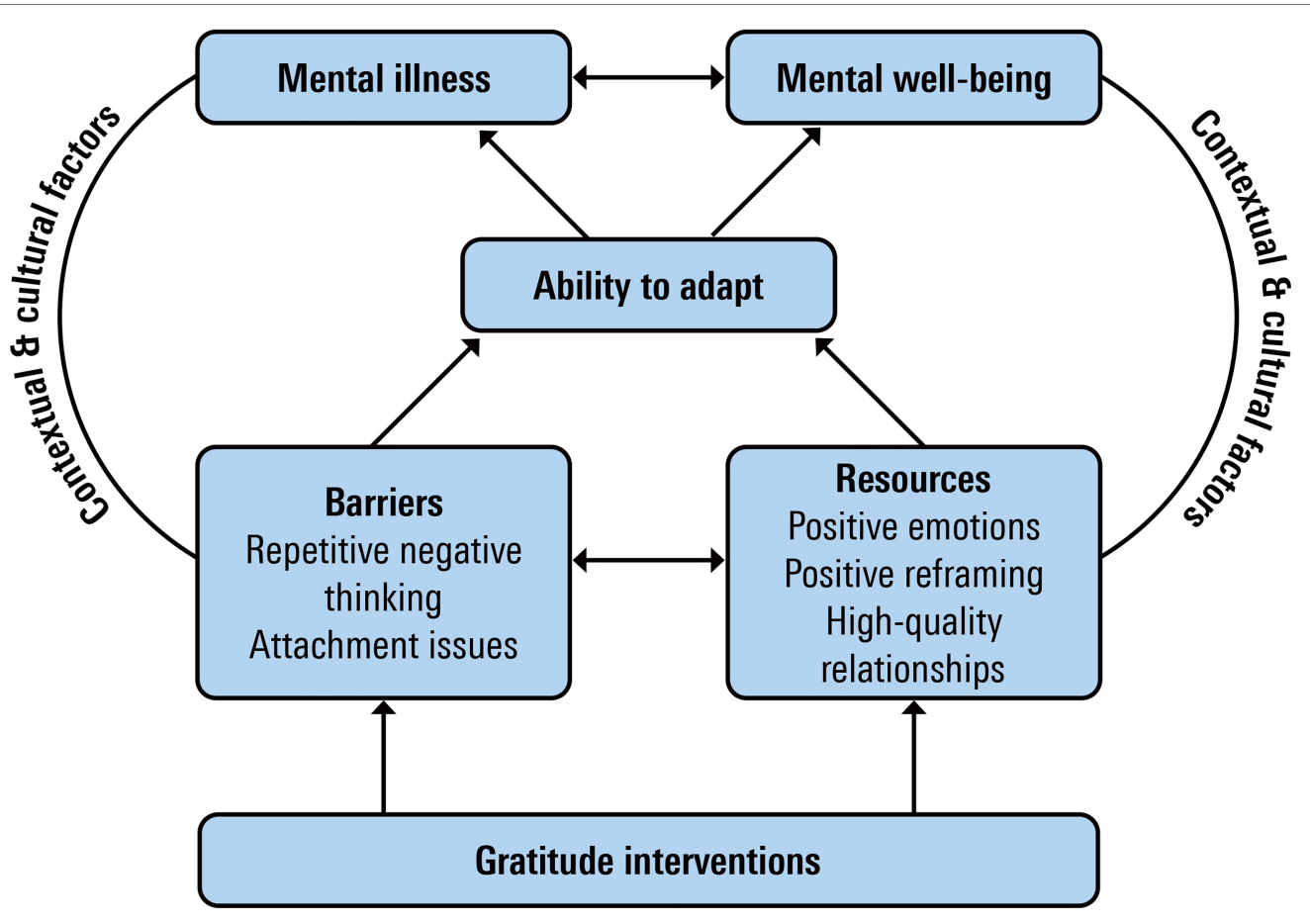

FIGURE 2 | Gratitude and model of sustainable mental health.

psychological treatment, several positive psychology inventions are often combined into so-called positive psychotherapy. Positive psychotherapy can be defined as a treatment approach that systematically amplifies the positive resources of clients, such as strengths, meaning, positive relationships, and intrinsically motivated accomplishment with aim of increasing mental wellbeing and personal recovery and undoing or diminishing mental illness (Rashid and Howes, 2016). How can positive psychotherapy be combined with treatments and interventions primarily aiming to reduce barriers for adaptation (complaint-oriented psychotherapy)? We discuss three potential modalities: positive psychotherapy as primary treatment, as a combinatorial treatment, and as personal recovery treatment.

Positive psychotherapy can be offered as primary treatment. Chaves et al., 2017 found that the effects of positive psychotherapy in reducing depressive symptomatology were similar to the effects of cognitive behavioral therapy (CBT) in a sample of women with a DSM-IV diagnosis of major depression. One explanation is that a lack of positive emotions and cognitions plays a major role in causing and maintaining depression (Gotlib and Joormann, 2010; Watson and NaragonGainey, 2010; Carl et al., 2013) and positive psychotherapy is primarily aimed at increasing positive emotions and cognitions. Though evidence-based treatments for depression, such as CBT, have been established (Cuijpers et al., 2011), it has also been estimated that about $10-60 \%$ of patients with depressive disorders do not respond to evidence-based treatments (Carvalho and Mcintyre, 2015). Moreover, about $20 \%$ of patients with a depressive disorder develop a chronic or therapy-resistant course (Kerkhof, 2002; Spijker et al., 2002). Possibly some patients may respond better to positive psychotherapy. Analyses using the Personalized Advantage Index showed that patients mental and physical comorbidity, prior antidepressant medication, higher levels of negative cognitions, and higher personal growth demonstrated a better response to positive psychotherapy in comparison with CBT (Lopez-Gomez et al., 2019). However, more research on factors predicting response to specific treatments is warranted.

Implementing positive psychotherapy as a combinatorial treatment is a second modality. One example is sequential treatment that can be defined as a two-stage approach, based on the a priori assumption that one treatment will often not be successful in realizing complete recovery or full response (Guidi et al., 2016). For example, studies have found larger effects on mental health for sequential combinations of CBT and wellbeing therapy in comparison with active control groups for people with cyclothymic disorder (Fava et al., 2011) and people with acute coronary syndromes (Rafanelli et al., 2020). Though wellbeing therapy differs from positive psychotherapy, these treatments share a primary focus on increasing psychological wellbeing. Within the model of sustainable mental health, sequential treatment may imply that a treatment primarily targeting barriers for adaptation is followed by a treatment primarily focusing on increasing resources for adaptation. A second example is implementing positive psychotherapy as a relapse prevention or rehabilitation intervention. Radstaak et al. (2020) evaluated the impact of an intervention combining wellbeing therapy 
and positive psychology as a rehabilitation intervention for people who had been treated for PTSD. For patients with lower levels of wellbeing, indicating the absence of complete recovery, the positive intervention was more effective than treatment as usual for mental wellbeing and posttraumatic growth.

A third modality is implementing positive psychotherapy as an intervention for personal recovery and wellbeing. This is especially relevant for people with severe mental illness (SMI) that can be defined a psychiatric disorder with severe functional problems, where the constraints are causal and consequential and which is not temporary, and there is a need for coordinated professional care (Delespaul, 2013). Examples of SMIs based on these criteria are schizophrenia, schizoaffective disorder, bipolar disorder (BD), personality disorder, and major depressive disorders (MDD). Several positive psychotherapy programs in this context have been developed. For example, WELLFOCUS is a positive psychotherapy group program adapted for people with psychosis. A trial with 94 participants showed no significant effects for mental wellbeing but small to moderate effects for various symptoms of mental ill-being in comparison with treatment as usual (Schrank et al., 2016). Another example is the Living well with mental disorder intervention (Kraiss et al., 2018). This is an 8-week transdiagnostic positive psychotherapy group intervention for people with SMI. Kraiss et al. (2018) conducted a trial on the effects of this intervention in a sample of 97 patients with bipolar disorder. The post-treatment findings show a moderate to large effect on mental wellbeing and personal recovery in comparison with treatment as usual (Kraiss, 2021). Recently, a meta-analysis on the effects of PPIs on mental health in people with SMI across studies was conducted (Geerling et al., 2020). Sixteen studies were included (nine RCTs), representing 729 patients. The results showed that there is at present no evidence that PPIs are more effective in comparison with other active interventions. However, withingroup effects revealed a moderate effect (Hedge's $g=0.40$ ) on wellbeing and a large effect on mental ill-being symptomatology $(g=0.70)$, suggesting that people with SMI do benefit from PPIs in terms of enhancement of mental health.

\section{IMPLICATIONS FOR FUTURE RESEARCH}

In the last section, we discussed gratitude as an example of one PPI and tried to explain the pathways through which it can have effects on both mental wellbeing and mental illness as outcomes. Overall, it has been discussed that it is difficult to demonstrate the superiority of one intervention type over another as most psychological interventions have some kind of effect on mental illness (Lambert, 2013a; Lambert, 2013b). This might apply to effects on mental wellbeing as well. Hence, it would be of value to conduct similar exercises for other kinds of interventions, thereby filling the model with different resources, aspects of adaptation, and pathways to outcomes. This could help to better understand what the main outcomes and working mechanisms of different forms of interventions in clinical samples are.

Although the model is informed by empirical research, it is mainly a theoretical proposition. A next step would be to further substantiate the model with empirical studies. This would provide more insight into the validity of the heuristic model for specific PPIs. Structural equation modeling could be used to examine the validity of the model. Researchers would need to make good choices for instruments to measure the different components in the model, but they would also need to have good longitudinal designs to assess the processes involved. Intervention studies assessing the impact of PPIs on mental health could include measures of adaptation, barriers, and resources and mediational analyses could study the specific processes of change as predicted by the model of sustainable mental health. This would also include research on the different modalities of combining PPIs and other psychological interventions. Besides demonstrating that interventions do have an effect on mental health outcomes, this would therefore also involve research that gives a better understanding what works when for whom.

This research agenda would also entail innovations in research methods. For example, single-case designs with more measures for fewer participants can be used as they are rather flexible in tailoring research to the processes that are involved in specific interventions. Furthermore, the APA describes including professional expertise and patient perspectives as important besides scientific evidence for effectiveness. These perspectives can add to filling in the model for particular interventions, but they can also inform theory on good, shared decision making about modalities and what works when for whom.

The model for sustainable mental health we presented in this position paper primarily applies to clinical psychology and psychiatry and not to public mental health and prevention. We also realize that the model is most relevant to western countries with a developed capacity for mental healthcare. It has been shown that most positive psychology research has been conducted in western, educated, industrialized, rich, and democratic (WEIRD) samples (Hendriks et al., 2018). It is also important to stress that wellbeing is strongly influenced by social and cultural contexts (McNulty and Fincham, 2011). For example, wellbeing literacy has been introduced as a vital capability to comprehend and compose wellbeing language across contexts in order to improve wellbeing of self and others (Oades et al., 2020, 2021). Though the model for sustainable mental health acknowledges the relevance of contextual and cultural factors mental health, it was beyond the scope of this paper to discuss them.

\section{AUTHOR CONTRIBUTIONS}

All authors have written and equally contributed to the paper. 


\section{REFERENCES}

Algoe, S. B. (2019). Positive interpersonal relationships. Curr. Dir. Psychol. Sci. 28, 183-188. doi: 10.1177/0963721419827272

Algoe, S. B., Fredrickson, B. L., and Gable, S. L. (2013). The social functions of the emotion of gratitude via expression. Emotion 13, 605-609. doi: 10.1037/ a0032701

Algoe, S. B., Gable, S. L., and Maisel, N. C. (2010). It's the little things: everyday gratitude as a booster shot for romantic relationships. Pers. Relat. 17, 217-233. doi: 10.1111/j.1475-6811.2010.01273.x

Algoe, S. B., and Zhaoyang, R. (2016). Positive psychology in context: effects of expressing gratitude in ongoing relationships depend on enactor responsiveness. J. Posit. Psychol. 11, 399-415. doi: 10.1080/17439760.2015.1117131

Antonovsky, A. (1993). The structure and properties of the sense of coherence scale. Soc. Sci. Med. 36, 725-733. doi: 10.1016/0277-9536(93)90033-Z

Barlow, J., Wright, C., Sheasby, J., Turner, A., and Hainsworth, J. (2002). Selfmanagement approaches for people with chronic conditions: a review. Patient Education Counseling 48, 177-187. doi: 10.1016/S0738-3991(02)00032-0

Bohlmeijer, E. T., Kraiss, J., Watkins, P., and Schotanus-Dijkstra, M. (2021). Promoting gratitude as a resource for sustainable mental health: results of a 3-armed randomized controlled trial up to 6 months follow-up. J. Happiness Stud. 22, 1011-1032. doi: 10.1007/s10902-020-00261-5

Bohlmeijer, E. T., Lamers, S. M. A., and Fledderus, M. (2015). Flourishing in people with depressive symptomatology increases with acceptance and commitment therapy. Post-hoc analyses of a randomized controlled trial. Behav. Res. Ther. 65, 101-106. doi: 10.1016/j.brat.2014.12.014

Bohlmeijer, E. T., and Westerhof, G. J. (2021). "A new model for sustainable mntal health: integrating well-being into psychological treatment," in Making an Impact on Mental Health: The Applications of Psychological Research. eds. J. N. Kirby and P. Gilbert (New York: Routledge), 153-188.

Brennan, K. A., Clark, C. L., and Shaver, P. R. (1998). "Self-report measurement of adult attachment: an integrative overview," in Attachment Theory and Close Relationships. eds. J. A. Simpson and W. S. Rholes (Washington: The Guilford Press), 46-76.

Bronfenbrenner, U. (1995). "Developmental ecology through space and time: a future perspective," in Examining Lives in Context: Perspectives on the Ecology of Human Development. eds. P. Moen, G. H. Elder and K. Lüscher (Washington: American Psychological Association), 619-647.

Carl, J. R., Soskin, D. P., Kerns, C., and Barlow, D. H. (2013). Positive emotion regulation in emotional disorders: a theoretical review. Clin. Psychol. Rev. 33, 343-360. doi: 10.1016/j.cpr.2013.01.003

Carr, A., Cullen, K., Keeney, C., Canning, C., Mooney, O., and Chinseallaigh, E. (2020). Effectiveness of positive psychology interventions: a systematic review and meta-analysis. J. Posit. Psychol., 1-21. doi: 10.1080/17439760.2020.1818807

Carvalho, A.F., and Mcintyre, R.S. (2015) Treatment Resistant Mood Disorder. Oxford: Oxford University Press.

Chakhssi, F., Kraiss, J. T., Sommers-Spijkerman, M., and Bohlmeijer, E. T. (2018). The effects of positive psychology interventions on well-being and distress in clinical samples with psychiatric or somatic disorders: a systematic review and meta-analysis. BMC Psychiatry 18, 1-17. doi: 10.1186/s12888-018-1739-2

Chaves, C., Lopez-Gomez, I., Hervas, G., and Vazquez, C. (2017). A comparative study on the efficacy of a positive psychology intervention and a cognitive behavioral therapy for clinical depression. Cogn. Ther. Res. 41, 417-433. doi: 10.1007/s10608-016-9778-9

Ciarrochi, J., and Kashdan, T. B. (2013). “The foundations of flourishing," in Mindfulness, Acceptance and Positive Psychology. eds. T. B. Kashdan and J. Ciarrochi (Oakland: New Harbinger Press), 1-29.

Cuijpers, P., Andersson, G., Donker, T., and van Straten, A. (2011). Psychological treatment of depression: results of a series of meta-analyses. Nord. J. Psychiatry 65, 354-364. doi: 10.3109/08039488.2011.596570

Davis, D. E. (2016). Thankful for the little things: a meta-analysis of gratitude interventions. J. Couns. Psychol. 63, 20-31. doi: 10.1037/cou0000107

De Vos, J. A., LaMarre, A., Radstaak, M., Bijkerk, C. A., Bohlmeijer, E. T., and Westerhof, G. J. (2017). Identifying fundamental criteria for eating disorder recovery: a systematic review and qualitative meta-analysis. J. Eat. Disord. 5, 1-14. doi: 10.1186/s40337-017-0164-0

De Vos, J. A., Radstaak, M., Bohlmeijer, E. T., and Westerhof, G. J. (2018). Having an eating disorder and still being able to flourish? Examination of pathological symptoms and well-being as two continua of mental health in a clinical sample. Front. Psychol. 9:2145. doi: 10.3389/fpsyg.2018.02145

Delespaul, P. H. (2013). Consensus over de definitie van mensen met een ernstige psychische aandoening (EPA) en hun aantal in Nederland. Tijdschrift. voor. Psychiatri. juni. 55, 427-438.

Dickens, L. R. (2017). Using gratitude to promote positive change: a series of meta-analyses investigating the effectiveness of gratitude interventions. Basic Appl. Soc. Psychol. 39, 193-208. doi: 10.1080/01973533.2017.1323638

Diener, E. (1984). Subjective well-being. Psychol. Bull. 95, 542-575. doi: 10.1037/0033-2909.95.3.542

Diener, E., Lucas, R. E., and Oishi, S. (2018). Advances and open questions in the science of subjective well-being. Collabra. Psychol. 4:15. doi: 10.1525/ collabra. 115

Diener, E., Suh, E. M., Lucas, R., and Smith, H. L. (1999). Subjective wellbeing: three decades of progress. Psychol. Bull. 125, 276-302. doi: 10.1037/0033-2909.125.2.276

Disabato, D. J., Kashdan, T. B., Short, J. L., and Jarden, A. (2017). What predicts positive life-events that influence the course of depression? A longitudinal examination of gratitude and meaning in life. Cogn. Ther. Res. 41, 444-458. doi: 10.1007/s10608-016-9785-x

Emmons, R.A. (2013). Gratitude Works. San Francisco: Jossey-Bass.

Fava, G. A., and Guidi, J. (2020). The pursuit of euthymia. World Psychiatry 19, 40-50. doi: 10.1002/wps.20698

Fava, G. A., Rafanelli, C., Tomba, E., Guidi, J., and Grandi, S. (2011). The sequential combination of cognitive Behavioral treatment and well-being therapy in cyclothymic disorder. Psychother. Psychosom. 80, 136-143. doi: $10.1159 / 000321575$

Fledderus, M., Bohlmeijer, E. T., Pieterse, M. E., and Schreurs, K. G. M. (2015). Acceptance and commitment therapy as guided self-help for psychological distress and positive mental health: a randomized controlled trial. Psychol. Med. 42, 485-495. doi: 10.1017/S0033291711001206

Franken, C. P. M., Lamers, S. M. A., Ten Klooster, P. M., Bohlmeijer, E. T., and Westerhof, G. J. (2018). Validation of the mental health continuumShort form and the dual continua model of well-being and psychopathology in an adult mental health setting. J. Clin. Psychol. 74, 2187-2202. doi: 10.1002/jclp.22659

Fredrickson, B. (2001). The role of positive emotions in positive psychology: The broaden-and-build theory of positive emotions. Am. Psychol. 56, 218-226. doi: 10.1037/0003-066X.56.3.218

Fredrickson, B. L., and Joiner, T. (2002). Positive emotions trigger upward spirals toward emotional well-being. Psychol. Sci. 13, 172-175. doi: 10.1111/1467-9280.00431

Geerling, B., Kraiss, J. T., Kelders, S. M., Stevens, A. W. M. M., Kupka, R. W., and Bohlmeijer, E. T. (2020). The effect of positive psychology interventions on well-being and psychopathology in patients with severe mental illness: a systematic review and meta-analysis. J. Posit. Psychol. 15, 572-587. doi: $10.1080 / 17439760.2020 .1789695$

Gotlib, I. H., and Joormann, J. (2010). Cognition and depression: current status and future directions. Annu. Rev. Clin. Psychol. 6, 285-312. doi: 10.1146/ annurev.clinpsy.121208.131305

Grant, A. M., and Gino, F. (2010). A little thanks goes a long way: explaining why gratitude expressions motivate prosocial behavior. J. Pers. Soc. Psychol. 98, 946-955. doi: 10.1037/a0017935

Grant, F., Guille, C., and Sen, S. (2013). Well-being and the risk of depression under stress. PLoS One 8:e67395. doi: 10.1371/journal.pone.0067395

Guidi, J., Tomba, E., and Fava, G. A. (2016). The sequential integration of pharmacotherapy and psychotherapy in the treatment of major depressive disorder: a meta-analysis of the sequential model and a critical review of the literature. Am. J. Psychiatr. 173, 128-132. doi: 10.1176/appi.ajp.2015.15040476

Hayes, S. C., Levin, M. E., Plumb-Vilardaga, J., Villatte, J. L., and Pistorello, J. (2013). Acceptance and commitment therapy and contextual behavioral science: the progress of a distinctive model of behavioral and cognitive therapy. Behav. Ther. 44, 180-198. doi: 10.1016/j.beth.2009.08.002

Heckendorf, H., Lehr, D., Ebert, D. D., and Freund, H. (2019). Efficacy of an internet and app-based gratitude intervention in reducing repetitive negative thinking and mechanisms of change in the intervention's effect on anxiety and depression: results from a randomized controlled trial. Behav. Res. Ther. 119:103415. doi: 10.1016/j.brat.2019.103415 
Hendriks, T., Warren, M. A., Schotanus-Dijkstra, M., Hassankhan, A., Graafsma, T., Bohlmeijer, E. T., et al. (2018). How weird are positive psychology interventions? A bibliometric analysis of randomized controlled trials on the science of well-being. J. Posit. Psychol. 14, 489-501. doi: $10.1080 / 17439760.2018 .1484941$

Huppert, F. A., and Whittington, J. E. (2003). Evidence for the independence of positive and negative well-being: implications for quality of life assessment. Br. J. Health Psychol. 8, 107-122. doi: 10.1348/135910703762879246

Iasiello, M., van Agteren, J., Schotanus-Dijkstra, M., Lo, L., and Westerhof, G. J. (in press). A systematic review and meta-analytic structural equation modelling of the mental health continuum - Short form to assess mental well-being. Assessment 28, 1434-1444.

Jeste, D. V., and Palmer, B. W. (2015). Positive Psychiatry, a Clinical Handbook American Psychiatric Publishing.

Kashdan, T. B., and Rottenberg, J. (2010). Psychological flexibility as a fundamental aspect of health. Clin. Psychol. Rev. 30, 865-878. doi: 10.1016/j.cpr.2010.03.001

Kashdan, T. B., Uswatte, G., and Julian, T. (2006). Gratitude and hedonic and eudaimonic well-being in Vietnam war veterans. Behav. Res. Ther. 44, 177-199. doi: $10.1016 /$ j.brat.2005.01.005

Kerkhof, A. J. F. M. (2002). "Chronische Depressie en Suicide," In Behandelstrategieën bij Chronische Depressie en Dysthymie. eds. M. Blom, J. Spijker and R. van Dyck (Houten: Bohn Stafleu Van Loghum, Cure and Care Development), 45-61.

Keyes, C. L. M. (2005). Mental illness and/or mental health? Investigating axioms of the complete state model of health. J. Consult. Clin. Psychol. 73, 539-548. doi: 10.1037/0022-006X.73.3.539

Keyes, C. L. M., Dhingra, S. S., and Simoes, E. J. (2010). Change in level of positive mental health as a predictor of future risk of mental illness. Am. J. Public Health 100, 2366-2371. doi: 10.2105/AJPH.2010.192245

Keyes, C. L. M., Wissing, M., Potgieter, J. P., Temane, M., Kruger, A., and van Rooy, S. (2008). Evaluation of the mental health continuum-short form (MHC-SF) in Setswana-speaking south Africans. Clinical Psychology and Psychotherapy 15, 181-192. doi: 10.1002/cpp.572

Kraiss, J.T. (2021). Living Well with Bipolar Disorder. Dissertation. Enschede: University of Twente

Kraiss, J. T., Peter, M., Chrispijn, M., Trompetter, H. R., Stevens, A., Neutel, E., et al. (2018). B-positive: a randomized controlled trial of a multicomponent positive psychology intervention for euthymic patients with bipolar disorder - study protocol and intervention development. BMC Psychiatry 18, 1-13. doi: 10.1186/s12888-018-1916-3

Lambert, M. J. (2013a). Outcome in psychotherapy: the past and important advances. Psychotherapy 50, 42-51. doi: 10.1037/a0030682

Lambert, M.J. (2013b). Bergin and Garfield's Handbook of Psychotherapy and Behavior Change. Hoboken: Wiley.

Lambert, N. M., and Fincham, F. D. (2011). Expressing gratitude to a partner leads to more relationship maintenance behavior. Emotion 11, 52-60. doi: $10.1037 / \mathrm{a} 0021557$

Lambert, N. M., Fincham, F. D., and Stillman, T. F. (2012). Gratitude and depressive symptoms: the role of positive reframing and positive emotion. Cognit. Emot. 26, 615-633. doi: 10.1080/02699931.2011.595393

Lambert, N. M., Graham, S. M., Fincham, F. D., and Stillman, T. F. (2009). A changed perspective: how gratitude can affect sense of coherence through positive reframing. J. Posit. Psychol. 4, 461-470. doi: 10.1080/ 17439760903157182

Lamers, S. M. A., Glas, C. A. W., Westerhof, G. J., and Bohlmeijer, E. T. (2012). Longitudinal evaluation of the mental health continuum-Short form (MHC-SF). Eur. J. Psychol. Assess. 28, 290-296. doi: 10.1027/1015-5759/ a000109

Lamers, S. M. A., Westerhof, G. J., Bohlmeijer, E. T., Ten Klooster, P. M., and Keyes, C. L. M. (2011). Evaluating the psychometric properties of the mental health continuum-Short form (MHC-SF) in the Dutch population. J. Clin. Psychol. 67, 99-110. doi: 10.1002/jclp.20741

Lamers, S. M. A., Westerhof, G. J., Glas, C. A. W., and Bohlmeijer, E. T. (2015). The bidirectional relation between positive mental health and psychopathology in a longitudinal representative panel study. J. Posit. Psychol. 10, 1-8. doi: 10.1080/17439760.2015.1015156

Lazarus, R. S., and Folkman, S. (1984). Stress, Appraisal and Coping. New York, NY: Springer.
Leamy, M., Bird, V., Le Boutillier, C., Williams, J., and Slade, M. (2011). Conceptual framework for personal recovery in mental health: systematic review and narrative synthesis. Br. J. Psychiatry 199, 445-452. doi: 10.1192/ bjp.bp. 110.083733

Linley, P. A., Joseph, S., Harrington, S., and Wood, A. M. (2006). Positive psychology, past, present and (possible) future. J. Posit. Psychol. 1, 3-16. doi: $10.1080 / 17439760500372796$

Linton, M. J., Dieppe, P., and Medina-Lara, A. (2010). Review of 99 self-report measures for assessing well-being in adults: exploring dimensions of wellbeing and developments over time. BMJ Open 6:e010641. doi: 10.1136/ bmjopen-2015-010641

Livneh, H. (2001). Psychological adaptation to chronic illness and disability: a conceptual framework. RCB 44, 151-160. doi: 10.1177/00343552010440305

Lopez-Gomez, I., Lorenzo-Luaces, L., Chaves, C., Hervas, G., DeRubeis, R. J., and Vazquez, C. (2019). Predicting optimal interventions for clinical depression: moderators of outcomes in a positive psychological intervention vs. cognitive behavioral therapy. Gen. Hosp. Psychiatry 61, 104-110. doi: 10.1016/j. genhosppsych.2019.07.004

Loriq, K. R., and Holman, H. (2003). Self-management education: history, definition, outcomes, and mechanisms. Annu. Behav. Med. 26, 1-7. doi: 10.1207/S15324796ABM2601_01

Lyubomirsky, S., Sheldon, K., and Schkade, D. (2005). Pursuing happiness: the architecture of sustainable change. Rev. Gen. Psychol. 9, 111-131. doi: 10.1037/1089-2680.9.2.111

McCullough, M. E., Emmons, R. A., and Tsang, J. A. (2002). The grateful disposition: a conceptual and empirical topography. J. Pers. Soc. Psychol. 82, 112-127. doi: 10.1037/0022-3514.82.1.112

McNulty, J. K., and Fincham, F. D. (2011). Beyond positive psychology? Toward a contextual view of psychological processes and well-being. Am. Psychol. 67, 101-110. doi: 10.1037/a0024572

Mikulincer, M., and Shaver, P. R. (2009). "Does gratitude promote social behaviour? Tbe moderating role of attachment security," in Prosocial Motives, Emotions and Behaviour. eds. M. Mikulincer and P. R. Shaver (Washington D.C.: American Psychological Association), 267-283.

Millstein, R. A., Celano, C. M., Beale, E. E., Beach, S. R., Suarez, L., Belcher, A. M., et al. (2016). The effects of optimism and gratitude on adherence, functioning and mental health following an acute coronary syndrome. Gen. Hosp. Psychiatry 43, 17-22. doi: 10.1016/j.genhosppsych.2016.08.006

Oades, L. G., Jarden, A., Hou, H., Ozturk, C., Williams, P., Slemp, G. R., et al. (2021). Wellbeing literacy: a capability model for wellbeing science and practice. Int. J. Environ. Res. Public Health 18:719. doi: 10.3390/ ijerph18020719

Oades, L. G., Ozturk, C., Hou, H., and Slemp, G. R. (2020). Wellbeing literacy: a language-use capability relevant to wellbeing outcomes of positive psychology intervention. J. Posit. Psychol. 15, 696-700. doi: 10.1080/17439760.2020.1789711

Radstaak, M., Huning, L., and Bohlmeijer, E. T. (2020). Well-being therapy as rehabilitation therapy for patients with PTSD-symptoms: a randomized controlled trial. Journal of posttraumatic disorder 33, 813-823. doi: 10.1002/ jts.22671

Rafanelli, C., Gostoli, S., Buzzichelli, S., Guidi, J., Sirri, L., Gallo, P., et al. (2020). Sequential combination of cognitive-behavioral treatment and wellbeing therapy in depressed patients with acute coronary syndromes: a randomized controlled trial (TREATED-ACS study). Psychother. Psychosom. 89, 345-356. doi: 10.1159/000510006

Rashid, T., and Howes, R. N. (2016). "Positive psychotherapy: clinical application of positive psychology," in The Wiley Handbook of Positive Clinical Psychology. eds. A. M. Wood and J. Johnston (Hoboken: Wiley Blackwell), 321-348.

Ryan, R. M., and Deci, E. L. (2001). On happiness and human potentials: a review of research on hedonic and eudaimonic well-being. Annu. Rev. Psychol. 52, 141-166. doi: 10.1146/annurev.psych.52.1.141

Ryan, R. M., and Deci, E. L. (2017). Self-Determination Theory: Basic Psychological Needs in Motivation, Development, and Wellness. New York, The Guilford Press.

Ryff, C. D. (2014). Psychological well-being revisited: advances in the science and practice of Eudaimonia. Psychother. Psychosom. 83, 10-28. doi: $10.1159 / 000353263$

Schotanus-Dijkstra, M., Ten Have, M., Lamers, S. M. A., De Graaf, R., and Bohlmeijer, E. T. (2017). The longitudinal relationship between flourishing mental health and incident mood, anxiety and substance use disorders. Eur. J. Pub. Health 27, 563-568. doi: 10.1093/eurpub/ckw202 
Schrank, B., Brownell, T., Jakaite, Z., Larkin, C., Pesola, F., Riches, S., et al. (2016). Evaluation of a positive psychotherapy group intervention for people with psychosis: pilot randomized controlled trial. Epidemiol. Psychiatr. Sci. 25, 235-246. doi: 10.1017/S2045796015000141

Schueller, S. M., and Parks, A. C. (2014). The science of self-help, translating positive psychology research Into increased individual happiness. Eur. Psychol. 19, 145-155. doi: 10.1027/1016-9040/a000181

Seligman, M., and Csikszentmihalyi, M. (2000). Positive psychology: an introduction. Am. Psychol. 55, 5-14. doi: 10.1037/0003-066X.55.1.5

Seligman, M., Rashid, T., and Parks, A. (2006). Positive psychotherapy. Am. Psychol. 61, 774-788. doi: 10.1037/0003-066X.61.8.774

Sirois, F. M., and Wood, A. M. (2017). Gratitude uniquely predicts lower depression in chronic illness populations: a longitudinal study of inflammatory bowel disease and arthritis. Health Psychol. 36:122. doi: $10.1037 /$ hea0000436

Slade, M. (2010). Mental illness and well-being: the central importance of positive psychology and recovery approaches. BMC Health Serv. Res. 10, 1-14. doi: $10.1186 / 1472-6963-10-26$

Spijker, J., De Graaf, R., Bijl, R. V., Beekman, A. T. F., Ormel, J., and Nolen, W. A. (2002). Duration of major depressive episodes in the general population: results from the Netherlands mental health survey and incidence study (NEMESIS). Br. J. Psychiatry 181, 208-213. doi: 10.1192/bjp.181.3.208

Spinhoven, P., Drost, J., Hemert, B.van, and Penninx, B.W. (2015). Common rather than unique aspects of repetitive negative thinking are related to depressive and anxiety disorders and symptoms. J. Anxiety Disord. 33, 45-52. doi:10.1016/j.janxdis.2015.05.001.

Tedeschi, R. G., and Calhoun, L. G. (1995). Trauma and Transformation: Growing in the Aftermath of Suffering. Thousand Oaks, CA: Sage.

Tennen, H., and Affleck, G. (2005). "Benefit finding and benefit-reminding," in Handbook of Positive Psychology. eds. C. R. Snyder and S. J. Lopez (New York, NY: Oxford University Press), 584-597.

Thoits, P. A. (2011). Mechanisms linking social ties and support to physical and mental health. J. Health Soc. Behav. 52, 145-161. doi: $10.1177 / 0022146510395592$

Trompetter, H. R., Lamers, S. M. A., Westerhof, G. J., Fledderus, M., and Bohlmeijer, E. T. (2017). Both positive mental health and psychopathology should be monitored in psychotherapy: confirmation for the dual-factor model in acceptance and commitment therapy. Behav. Res. Ther. 91, 58-63. doi: $10.1016 /$ j.brat.2017.01.008

Vaillant, G. (2003). Mental health. Am. J. Psychiatr. 160, 1373-1384. doi: 10.1176/ appi.ajp.160.8.1373

Van Weeghel, J., Van Zelst, C., Boertien, D., and Hasson-Ohayon, I. (2019). Conceptualizations, assessments, and implications of personal recovery in mental illness: A scoping review of systematic reviews and meta-analyses. Psychiatric Rehabilitation Journal, 42, 169-181. doi: 10.1037/prj0000356

van Agteren, J., Iasiello, M., Lo, L., Bartholomaeus, J., Kopsaftis, Z., Carey, M., et al., (2021). A systematic review and meta-analysis of psychological interventions to improve mental wellbeing. Nat. Hum. Behav. 5, 631-652. doi:10.1038/s41562-021-01093-w

Waterman, A. (1993). Two conceptions of happiness: contrasts of personal expressiveness (eudaimonia) and hedonic enjoyment. J. Pers. Soc. Psychol. 64, 678-691. doi: 10.1037/0022-3514.64.4.678
Watkins, P. C., Cruz, L., Holben, H., and Kolts, R. L. (2008). Taking care of business? Grateful processing of unpleasant memories. J. Posit. Psychol. 3, 87-99. doi: 10.1080/17439760701760567

Watkins, P. C., Woodward, K., Stone, T., and Kolts, R. L. (2003). Gratitude and happiness: development of a measure of gratitude, and relationships with subjective well-being. Soc. Behav. Pers. 31, 431-451. doi: 10.2224/sbp.2003.31.5.431

Watson, D., and Naragon-Gainey, K. (2010). On the specificity of positive emotional dysfunction in psychopathology: evidence from the mood and anxiety disorders and schizophrenia/schizotypy. Clin. Psychol. Rev. 30, 839-848. doi: 10.1016/j.cpr.2009.11.002

Weich, S., Brugha, T., McBride, O., and Stewart-Brown, S. (2011). Mental wellbeing and mental illness: findings from the adult psychiatric morbidity survey for England 2007. Br. J. Psychiatry 199, 23-28. doi: 10.1192/bjp.bp.111.091496

Westerhof, G. J., and Bohlmeijer, E. T. (2012). Life stories and mental health: The role of identification processes in theory and interventions. Narrative. Works: Issues. Investigations. Interventions 2, 107-128.

Westerhof, G. J., and Keyes, C. L. M. (2010). Mental illness and mental health: The two continua model across the lifespan. J. Adult Dev. 17, 110-119. doi: 10.1007/s10804-009-9082-y

White, R. G., Gregg, J., Batten, S., Hayes, L. L., and Kasujja, R. (2017). Contextual behavioral science and global mental health: synergies and opportunities. J. Contextual Behav. Sci. 6, 245-251. doi: 10.1016/j.jcbs.2017.07.001

Wood, A. M., Froh, J. J., and Geraghty, A. W. A. (2010). Gratitude and wellbeing: a review and theoretical integration. Clin. Psychol. Rev. 30, 890-905. doi: $10.1016 /$ j.cpr.2010.03.005

Wood, A. M., and Johnston, J. (2016). The Wiley Handbook of Positive Clinical Psychology. Hoboken, Wiley Blackwell.

Wood, A. M., and Joseph, S. (2010). The absence of positive psychological (eudemonic) well-being as a risk factor for depression: A ten year cohort study. J. Affect. Disord. 122, 213-217. doi: 10.1016/j.jad.2009.06.032

Wood, A. M., and Tarrier, N. (2010). Positive clinical psychology: a new vision and strategy for research and practice. Clin. Psychol. Rev. 30, 819-829. doi: 10.1016/j.cpr.2010.06.003

World Health Organization. (2005). Promoting Mental Health: Concepts, Emerging Evidence, Practice. Geneva: WHO.

Conflict of Interest: The authors declare that the research was conducted in the absence of any commercial or financial relationships that could be construed as a potential conflict of interest.

Publisher's Note: All claims expressed in this article are solely those of the authors and do not necessarily represent those of their affiliated organizations, or those of the publisher, the editors and the reviewers. Any product that may be evaluated in this article, or claim that may be made by its manufacturer, is not guaranteed or endorsed by the publisher.

Copyright $\odot 2021$ Bohlmeijer and Westerhof. This is an open-access article distributed under the terms of the Creative Commons Attribution License (CC BY). The use, distribution or reproduction in other forums is permitted, provided the original author(s) and the copyright owner(s) are credited and that the original publication in this journal is cited, in accordance with accepted academic practice. No use, distribution or reproduction is permitted which does not comply with these terms. 